\title{
TEKNIK MITIGASI HARMONISA MENGGUNAKAN LINE REACTOR
}

\author{
Ali Mashar*, Dja'far Sodiq** \\ *Jurusan Teknik Konversi - Politeknik Negeri Bandung, Jl. Gegerkalong Hilir Ds. Ciwaruga Bandung, Telp. \\ 022-2013789, ekst.150,Fax.022-2013889, email: amashar69@gmail.com \\ ** Jurusan Teknik Konversi-Politeknik Negeri Bandung
}

\begin{abstract}
Abstrak
Sistem Pembangkit Listrik Tenaga Mikro Hidro (PLTMH) yang dibangun di Indonesia pada umumnya menggunakan Electronic Load Control (ELC) untuk mengatur daya dummy load (ballast) sesuai dengan perubahan daya yang diserap konsumen guna mempertahankan frekuensi. ELC dalam mengatur daya ke ballast tersebut dilakukan melalui rekayasa sinyal yang menggunakan Triac (transistor ac). Penerapan ELC inilah yang kemudian mengakibatkan timbulnya harmonisa yang sangat tinggi yang diukur dalam Total Harmonic Distortion (THD) di PLTMH sehingga mengganggu peralatan yang menggunakan daya listrik dari pembangkit tersebut seperti: peralatan komunikasi (audio visual) dan peralatan kontrol dan proteksi.

Pada penelitian ini dikaji teknik mengatasi masalah harmonisa tersebut dengan menggunakan Line Reactor untuk memitigasinya. Untuk mendapatkan hasil yang baik line reactor harus dirancang sesuai dengan karakteristik harmonisa dan generator yang digunakan. Oleh karena itu, pada paper ini juga dibahas tentang perancangan line reactor dan pemasangannya pada sistem PLTMH. Untuk mengetahui sejauhmana efektivitas line reactor dilakukan pengujian dan analisis unjuk kerjanya.

Berdasarkan hasil pengujian diperoleh hasil bahwa line reactor yang dirancang cukup efektif mengatasi masalah tersebut, yaitu mampu menurunkan harmonisa sampai dengan $35 \%$ walaupun ada konsekwensi penurunan tegangan jaringan.
\end{abstract}

Kata kunci:Electronic Load Control (ELC), ballast, Total Harmonic Distortion (THD)

\section{PENDAHULUAN}

\subsection{Latar Belakang}

Ada banyak permasalahan yang terkait dengan pembangkit listrik tenaga mikro hidro (PLTMH), di antaranya adalah masalah harmonisa. Sebagaimana telah dibahas secara mendalam pada [1] bahwa salah satu akar masalah yang menjadi penyebab harmonisa pada PLTMH adalah Electronic Load Control (ELC). Teknologi ELC diterapkan pada PLTMH dimaksudkan untuk menjaga frekuensi tegangan yang dibangkitkan agar relatif konstan.Frekuensi dijaga konstan dimaksudkan untuk mempertahankan sifat beban listrik (reaktansi) agar tidak berubah.

Peranan ELC ini pada pembangkitpembangkit listrik besar identik dengan sistem governor yang berfungsi untuk mempertahankan frekuensi bila sistem bekerja secara mandiri. Permasalahan yang terjadi dengan ELC ini adalah timbulnya harmonisa yang sangat tinggi yang bisa mengganggu kinerja sistem peralatan yang menggunakan listrik dari pembangkit tersebut.

Paper ini mengkaji permasalahan harmonisa pada PLTMH dan bagaimana mitigasinya dengan menggunakan line reactor.

\subsection{Prinsip PLTMH (review)}

Seperti yang telah dimuat pada [1], agar bisa mendapatkan gambaran secara utuh tentang paper ini, perlu mengulas kembali tentang prinsip kerja sistem PLTMH seperti yang ditunjukkan pada Gambar 1.

Komponen utama suatu PLTMH terdiri penstock, turbin air dan generator. Turbin air berfungsi untuk mengubah daya potensial air menjadi daya mekanik, sedangkan generator yang dikopel dengan turbin, mengkonversi daya mekanik poros menjadi daya listrik.

Jika menggunakan generator sinkron, ada dua alat bantu utama pembangkit agar mampu meberikan daya listrik dengan tegangan dan frekuensi konstan, yaitu Automatic Voltage Regulator (AVR) dan ELC[2][3]. AVR berfungsi untuk menjaga tegangan terminal generator konstan dengan mengatur arus eksitasi generator sedangkan ELC berfungsi untuk mengatur daya yang diserap oleh dummy load (ballast) sesuai perubahan daya yag diserap oleh konsumen sehingga daya keluaran generator selalu konstan sesuai dengan daya masukan dari turbinnya. 
PLTMH pada umumnya dirancang pada head (h) dan debit air (Q) konstan.Dengan demikian daya potensial air yang masuk ke turbin $\left(\mathrm{P}_{\mathrm{inT}}\right)$ juga konstan yang besarnya adalah:

$$
P_{i n T}=\rho g h Q \ldots \ldots(1)
$$

di mana:

$$
\begin{aligned}
& \mathrm{P}_{\text {inT }}=\text { daya masukan turbin }[\mathrm{W}] \\
& \rho=\text { massa jenis air }\left[\mathrm{kg} / \mathrm{m}^{3}\right] \\
& \mathrm{g}=\text { gravitasi bumi }\left[9,81 \mathrm{~m} / \mathrm{s}^{2}\right] \\
& \mathrm{h}=\text { ketinggian air }[\mathrm{m}] \\
& \mathrm{Q}=\text { debit air }\left[\mathrm{m}^{3} / \mathrm{s}\right]
\end{aligned}
$$

Daya air diubah oleh turbin menjadi daya mekanik poros atau $\mathrm{P}_{\text {ing }}$ yang besarnya adalah daya potensial air $\left(\mathrm{P}_{\mathrm{inT}}\right)$ dikalikan dengan efisiensi turbin, $\left(\mathrm{n}_{\mathrm{T}}\right)$ atau

$$
P_{i n G}=P_{i n T} . \eta_{T} \ldots
$$

Turbin dikopel dengan generatordan mesin inilah yang mengubah daya mekanik menjadi daya listrik. Bila daya potensial air tetap, maka daya masukan (poros) generator $\left(\mathrm{P}_{\mathrm{inG}}\right)$ juga konstan. Sementara itu, besar daya keluaran generator $\left(\mathrm{P}_{\mathrm{Gen}}\right)$ yang disuplaikan ke beban $\left(\mathrm{P}_{\text {Beban }}\right)$ selalu berubah sesuai dengan kebutuhan konsumen [1].

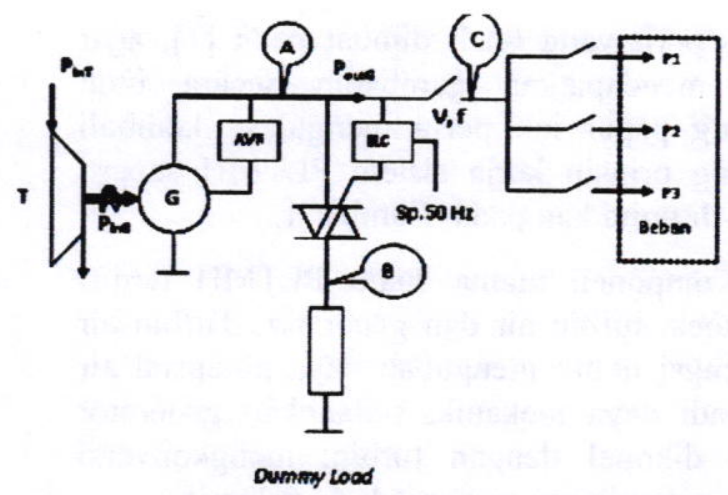

Gambar 1. Skematik PLTMH dengan ELC.

Agar frekuensi konstan, maka aksi pengendali ELC inilah yang menyerap daya lebihan generator yang tidak terserap sepenuhnya oleh beban sehingga total daya keluaran generator tetap konstan. Atau dapat dituliskan:

$$
\mathrm{P}_{\mathrm{Gen}}=\mathrm{P}_{\text {Beban }}+\mathrm{P}_{\text {Ballast }}=\text { konstan... }
$$

di mana:

$\mathrm{P}_{\mathrm{Gen}}=$ daya output generator [ $\left.\mathrm{kW}\right]$

$\mathrm{P}_{\text {Beban }}=$ daya yang diserap oleh konsumen (masyarakat) $[\mathrm{kW}]$
$\mathrm{P}_{\text {Ballast }}=$ daya yang diserap oleh dummy load (ballast) [kW]

\subsection{Unjuk Kerja ELC Eksisting}

Berdasarkan hasil kajian sebelumnya [1] Gambar 2 dan 3 menunjukkan kerja ELC pada sistem PLTMH yang digunakan sebagai obyek penelitian. Dengan daya beban yang berubahubah, tegangan terminal generator tetap konstan yang dijaga oleh AVR (Gbr. 2). Daya ballast selalu mengimbangi daya beban sehingga daya output total generator adalah konstan. Konstannya daya total generator menujukkan bahwa frekuensi terjaga konstan (Gbr. 3).

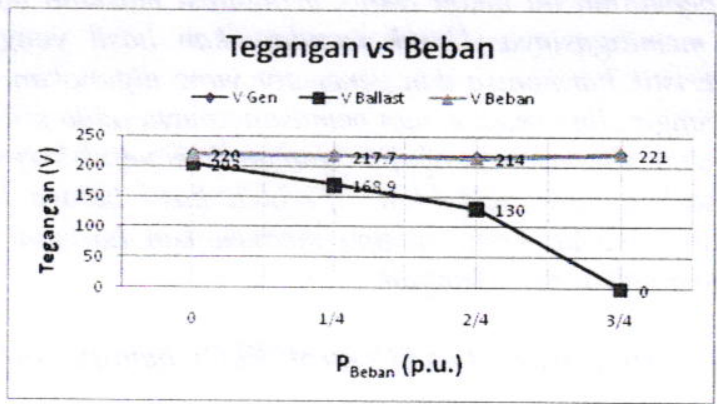

Gambar 2 Tegangan sebagai fungsi dari daya yang mengalir ke beban [1]

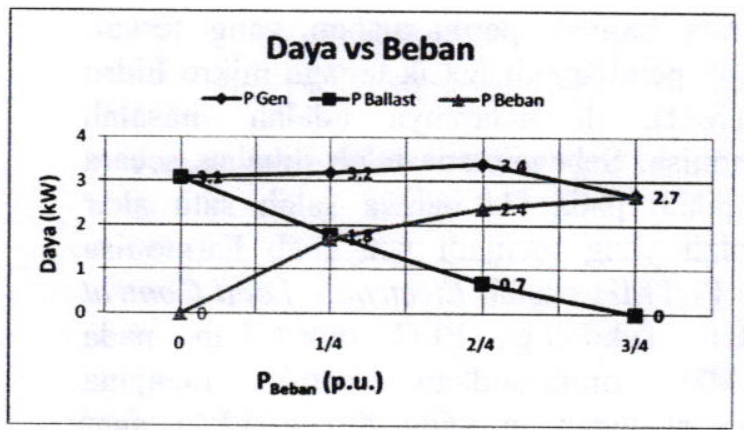

Gambar 3 Daya Generator, Ballast dan Beban sebagai fungsi $\mathrm{P}_{\text {Beban }}$ (p.u.) [1]

Ini menunjukkan bahwa AVR dan ELC bekerja dengan baik sesuai dengan fungsi yang diharapkan.

\subsection{Identifikasi Masalah}

Berdasarkan studi, didapatkan permasalahan bahwa ELC yang menggunakan triac dalam pengaturan daya ballastnya, merupakan sumber harmonisa [1]. Kandungan harmonisanya berubah bila beban berubahubah dan jauh melampaui batas maksimum yang ditentukan oleh IEEE 519-1992. 
Harmonisa arus dari ELC ini berdampak langsung pada tingginya harmonisa tegangan keluaran generator.

\subsection{Pengaruh harmonisa ballast terhadap keluaran generator}

Gambar 4 menunjukkan kurva THD-V dan THD-I pada sisi generator sebagai fungsi $\mathrm{P}_{\text {Ballast }} \mathrm{di}$ mana semakin tinggi daya yang diserap oleh ballast semakin menurun THD arusnya tetapi tidak demikian dengan THD tegangannya yang malah meningkat. THD-V= $18-22 \%$. (Spesifikasi generator: THD-V $<2 \%$ tanpa beban).

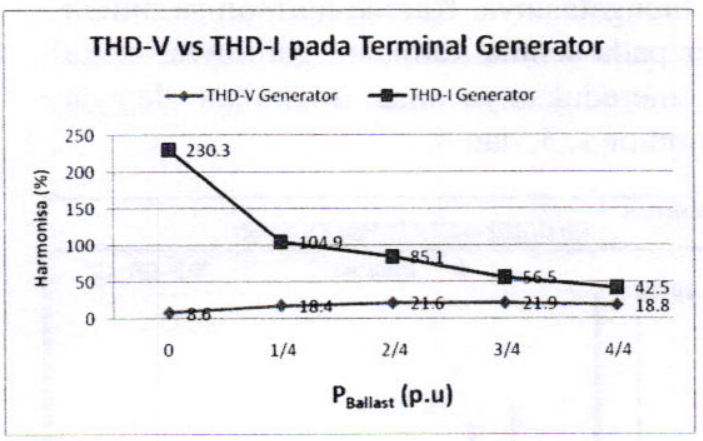

Gambar 4 Kurva THD-V, THD-I Generator sebagai fungsi $P_{\text {Ballast }}$ (p.u.)

Standard IEEE 519-1992: untuk general system: $\mathrm{THD}-\mathrm{V}=5 \%$ dan $\mathrm{TDD}=5 \%$ (untuk $\mathrm{I}_{\mathrm{SC}}<20 \mathrm{I}_{\mathrm{n}}$ ). Ini menunjukkan bahwa harmonisa yang timbul jauh melampaui standar.

\subsection{Jenis-jenis Filter Harmonisa}

Pada saat ini telah banyak ditemukan teknik mitigasi harmonisa sebagaimana diuraikan pada [4][5][6] mulai dari yang sederhana sampai dengan yang kompleks seperti yang secara garis besar dijelaskan berikut ini.

\section{1) Line-Reactor(LR)/Isolation Transformer}

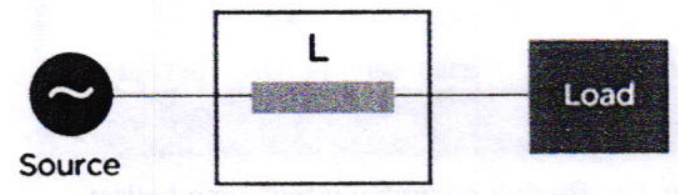

Gambar 6. Line Reactor Filter

Teknik mitigasi dengan line reactor filter merupakan teknik mitigasi yang paling sederhana. Biasanya berupa gawai berbasis induktor atau trafo isolasi yang dipasang sebelum beban. Sistem ini bisa mereduksi harmonisa sampai $50 \%$, namun dengan konsekwensi adanya tegangan jatuh yang relatif tinggi pada komponen induktor $(\mathrm{L})$.

2) Tuned Harmonic Filters

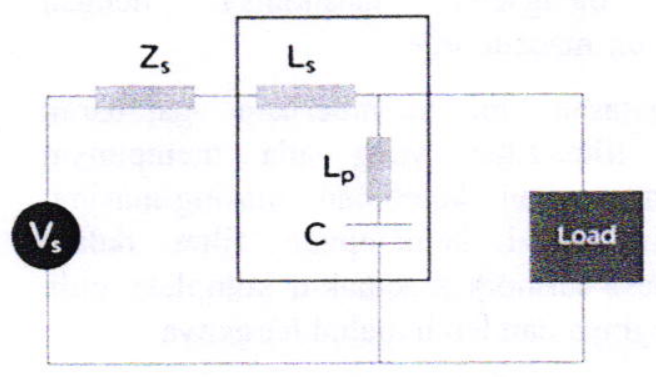

Gambar 7. Tuned Harmonic Filter

Ini merupakan passive filter yang terdiri dari induktor dan kapasitor. Induktor Lp dan kapasitor $\mathrm{C}$ memberikan saluran impedansi rendah untuk frekuensi tunggal dan induktor Ls diperlukan untuk detuned filter dari terjadinya resonansi antara jaringan sumber dan filter. Filter ini hanya memitigasi satu frekuensi saja, dan memberikan leading reactive current.

\section{3) Broadband Filters}

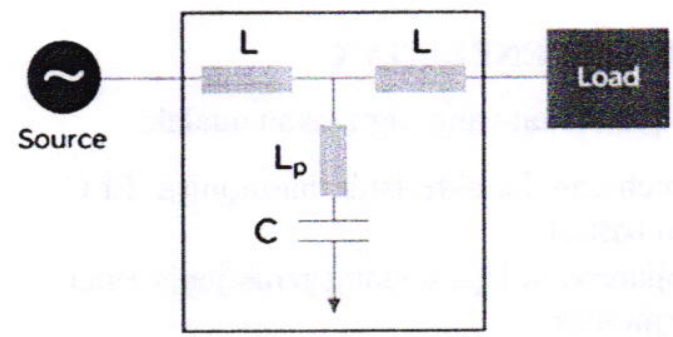

Gambar 8. Broadband harmonic filter

Filter ini cocok digunakan untuk memitigasi bermacam-macam frekuensi harmonisa, namun rugi-rugi panas meningkat dan jatuh tegangannya tinggi.

4) Active Harmonic Filter (AHF)

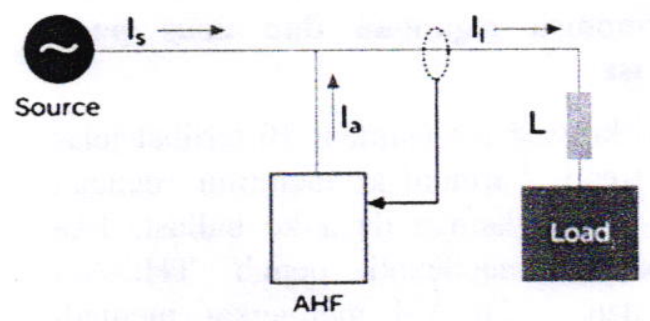

Gambar 9. Active harmonic filter (AHF)

Prinsip dari filter aktif adalah membangkitkan komponen-komponen harmonisa yang 
menetralisir komponen-komponen harmonisa dari beban non linier. Pada filter ini arus yang dibangkitkan oleh AHF diinjeksikan ke sistem guna menghilangkan harmonisa dari beban. AHF merupakan filter yang paling efektif untuk mengatasi harmonisa dengan bermacam-macam orde.

Penjelasan ini memberikan gambaran bahwa filter-filter yang ada mempunyai kekurangan dan kelebihan masing-masing. Semakin tinggi kemampuan filter dalam mengatasi harmonisa semakin kompleks pula teknologinya dan lebih mahal harganya.

Dasar pertimbangan untuk memilih sebuah filter harus didasari dengan pengetahuan tentang karakteristik harmonisa yang terjadi. Bila karakteristik harmonisa dapat diatasi dengan filter yang sederhana, tak perlu harus menggunakan filter yang lebih kompleks. Sama halnya dengan strategi yang digunakan dalam penelitian ini, teknik mitigasi dapat ditentukan setelah diketahui karakteristik harmonisa di PLTMH dengan sangat mempertim-bangkan aspek teknik dan ekonominya, yang harus sederhana dan murah.

\section{METODE PENELITIAN}

Metode penelitian yang digunakan adalah:

- Penentuan karakteristik harmonisa ELC dan ballast.

- Kajian teknologi tentang jenis-jenis filter harmonisa

- Rancang bangun filter

- Uji kinerja filter hasil rancang bangun

- Analisis unjuk kerja filter.

\section{HASIL DAN PEMBAHASAN}

\subsection{Karakteristik Harmonisa Ballast ELC}

- Harmonisa tegangan dan arus pada ballast

Dari kurva pada Gambar 10 terlihat jelas bahwa trend harmonisa menurun dengan semakin meningkatnya daya ke ballast. Jika daya ballast mendekati penuh THD-V/I $38,1 \%$, dan THD-V/I meningkat menjadi $168,3 \%$ ketika daya ballast mendekati nol. Dengan spektrum pada $\mathrm{P}_{\text {ballast }}=2 / 4$ p.u seperti yang ditunjukkan Gambar 11 dan bentuk gelombang tegangan seperti ditunjukkan pada Gambar 12.

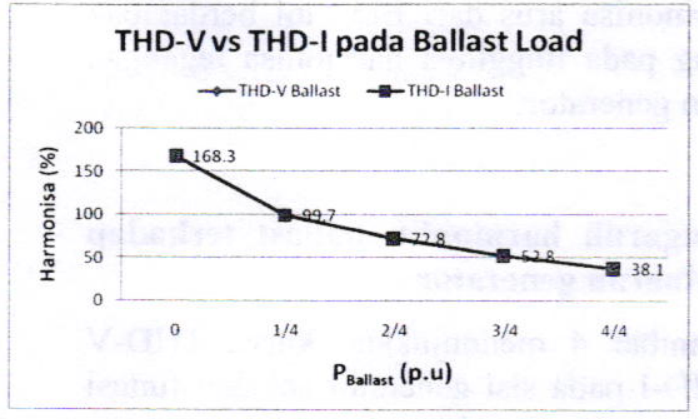

Gambar 10 Kurva THD-V, THD-I sebagai fungsi

$$
P_{\text {Ballast }} \text { (p.u.) }
$$

Timbul harmonisa pada frekuensi kelipatan 3, 5, 7 dan 9. Ini merupakan informasi yang sangat penting untuk melakukan tindak lanjut untuk mengatasinya. Karena harmonisa timbul hampir pada semua kelipatan ganjilnya, maka untuk mereduksinya bisa dilakukan dengan filter nomor 1,3 , dan 4 .

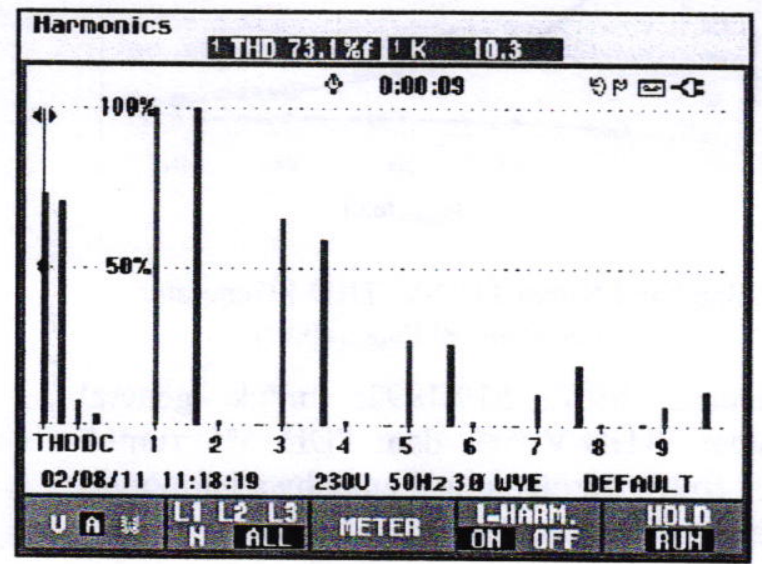

Gambar11. Spektrum harmonisa arus ballast pada $P_{\text {Ballast }}=2 / 4$ p.u.

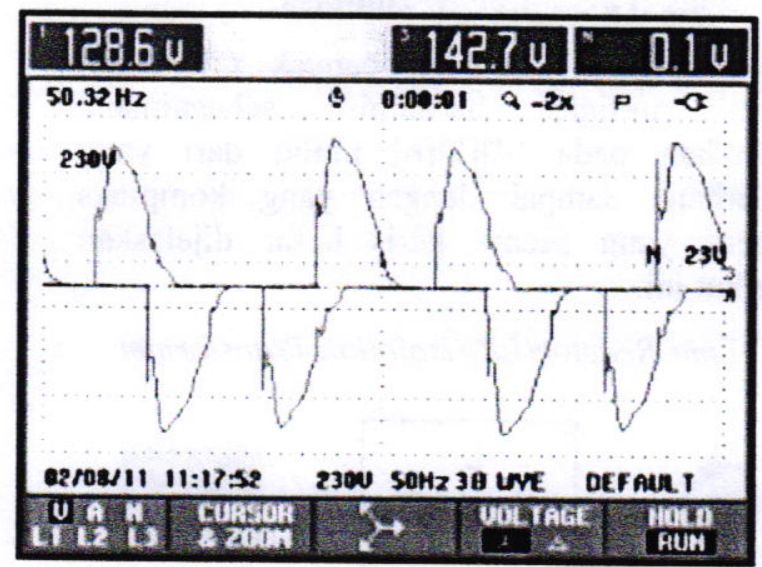

Gambar 12. Bentuk gelombang tegangan ballast pada $P_{\text {Ballast }}=2 / 4$ p.u.

Filter nomor 4 sangat efektif untuk semua haronisa, akan tetapi sangat kompleks dan mahal. Filter 3 sesuai untuk harmonisa pada banyak frekuensi tapi ada drop tegangan dan panas. 
Untuk menyelesaikan permasalahan diatas pada penelitian ini digunakan filter line reactor. Filter ini sangat sederhana, murah dan hampir tidak memerlukan pemeliharaan dan setting-setting khusus. Oleh karenanya sangat sesuai dengan kesederhanaan operator yang ada di lapangan.

\subsection{Rancang Bangun Filter Line Reactor}

Line Reactor merupakan induktor dengan harga induktansi (L) tertentu yang disamping mampu mereduksi harmonisa juga sebagai pelindung dari tegangan spike baik yang berasal dari dalam (switching) maupun dari luar (traveling wave). Nilai induktansi dirancang berdasarkan spesifikasi generator.

\section{- Perhitungan Induktansi dari Line Reactor (LR)}

Untuk menghitung induktansi dari line reactor dapat dilakukan seperti prosedur berikut ini. Line reactor untuk generator sinkron yang mempunyai spesifikasi: $30900 \mathrm{VA}, 380 \mathrm{~V}, 50$ $\mathrm{Hz}$.

1. Memilih harga dasar (base values). Sesuai dengan spesifikasi generator, ditentukan harga dasar: $\mathrm{VA}_{\text {base }}=30900$ $\mathrm{VA}, \mathrm{V}_{\text {base }}=380 \mathrm{~V}$, dan $\mathrm{f}_{\text {base }}=50 \mathrm{~Hz}$. Berdasarkan harga-harga dasar ini dapat diturunkan harga-harga dasar besaran lainnya.

2. Menghitung arus fasa stator dasar, $\mathrm{I}_{\mathrm{S} \text { (base) }}$ :

$\mathrm{I}_{\mathrm{S} \text { (base) }}=\mathrm{VA}_{\text {base }} /\left(\sqrt{3} \quad \mathrm{xV}_{\text {base }}\right)=30900 /($ $\sqrt{3} \times 380)=47 \mathrm{~A}$

3. Menghitung Impedansi stator dasar, $Z_{S(\text { base) }}$ :

$\mathrm{Z}_{\mathrm{S} \text { (base) }}=\mathrm{V}_{\text {base }}^{2} / \mathrm{VA}_{\text {base }}=380^{2} / 30900=$ $4,673 \Omega$

4. Menghitung Induktansi stator dasar, $\mathrm{L}_{\mathrm{S}}$ (base):

Resistansi belitan stator sangat kecil dan dapat diabaikan dalam perhitungan ini. $\mathrm{L}_{\mathrm{S} \text { (base) }}=\mathrm{Z}_{\mathrm{S} \text { (base) }} / \omega_{\text {base }}=4,673 / 314=$ $14,882 \mathrm{mH}$

\section{Spesifikasi Line Reactor}

Dalam menerapkan line reactor untuk mitigasi harmonisa harus memperhitungkan jatuh tegangan yang diperkenankan oleh standar, dalam hal ini adalah maksimum 5\%. Sesuai dengan ketentuan tersebut maka induktansi yang bisa diterapkan sebagai line reactor adalah:

$$
\mathrm{L}_{\text {reactor }}=0.05 \times \mathrm{L}_{\mathrm{S} \text { (base) }}=0.74 \mathrm{mH}
$$

Line reactor ini harus mempunyai kemampuan hantar arus di atas atau minimal sama dengan arus nominal generator. Agar akurasinya tinggi dalam penerapannya, line reactor ini harus memiliki resistansi yang sekecilkecilnya sehingga bila diperhitungkan tidak memiliki pengaruh yang signifikan pada impedansi sistem.

\section{- Perancangan Line Reactor}

Gambar 13 merupakan gambar skematik bangunan sebuah solenoid panjang yang digunakan sebagai dasar perancangan sebuah induktor [Marhall, S.V., 1987].

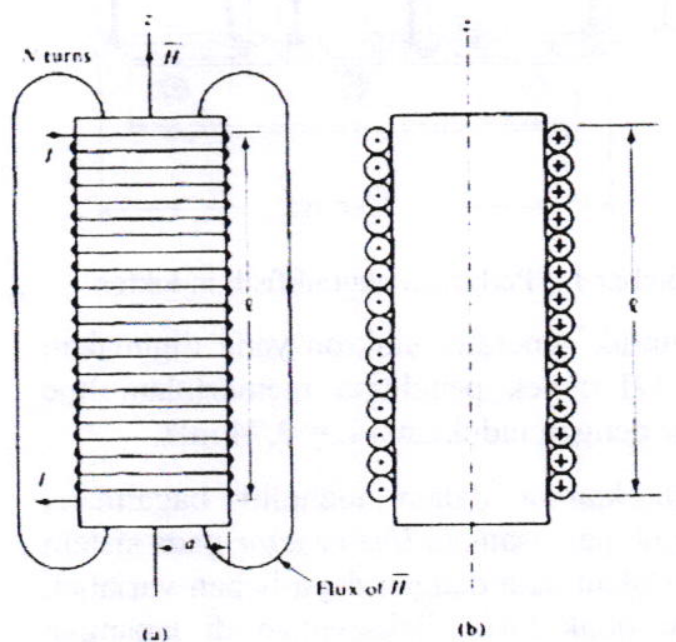

Gambar 13 Bangunan sebuah induktor

Induktansi diri pada solenoid panjang seperti yang ditunjukkan pada Gambar 4.19 dapat dihitung dengan menggunakan rumus:

$L=\frac{\mu N^{2} \pi a^{2}}{l}$ atau $\quad N=\sqrt{\frac{L \cdot l}{\mu \pi a^{2}}}$

di mana:

$$
\begin{aligned}
& L=\text { induktansi }[\mathrm{H}] \\
& \mu=\text { permeabilitas }\left(\mu_{r} \mu_{0}\right) \\
& N=\text { jumlah lilitan } \\
& a=\text { jari-jari }[\mathrm{m}] \\
& l=\text { panjang } \text { koil }[\mathrm{m}]
\end{aligned}
$$

Dari rumusan ini terlihat jelas bahwa induktansi induktor ditentukan oleh permeabilitas bahan, jumlah lilitan kawat, panjang kumparan, dan luasan efektif belitan. Untuk mendapatkan gambaran ukuran fisik induktor digunakan ukuran pendekatan seperti yang ditunjukkan pada Gambar 14. 
Mengapa ini merupakan ukuran pendekatan, karena dalam pembuatan line reactor untuk suatu harga induktansi tertentu perlu dilakukan pengesetan-pengesetan lagi dalam penyusunan intinya. Ukuran yang dibuat ini sudah diestimasi cukup untuk line reactor yang diperlukan. Ukuran yang paling penting dalam hal ini adalah induktansi (L) dan daya hantar arus maksimumnya (In).

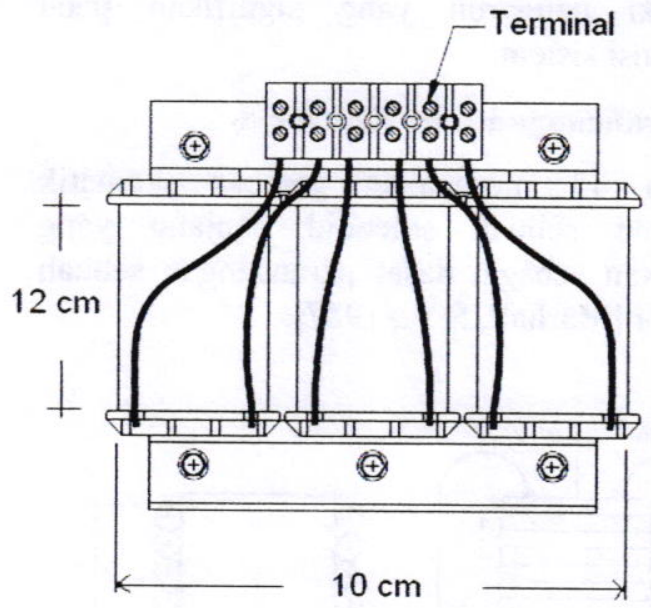

Gambar 14. Perkiraan ukuran fisik induktor

Jadi, untuk generator sinkron yang digunakan di PLTH obyek penelitian memerlukan line reactor dengan induktansi $\mathrm{L}=0,74 \mathrm{mH}$.

Namun karena dalam meneliti bagaimana pengaruh pemasangan line reactor pada sistem memerlukan data dengan daya beban variabel, hal ini tidak bisa dilaksanakan di lapangan secara langsung (beban PLTMH tidak dapat diatur-atur), maka pengujian alat ini dilakukan dilakukan di laboratorium. Untuk mendapatkan data yang bisa mewakili kondisi yang sebenarnya digunakan generator sinkron: $5 \mathrm{kVA}, 380 \mathrm{~V}, 7,6 \mathrm{~A}$, dan $50 \mathrm{~Hz}$. Sebagai prime mover digunakan motor $\mathrm{dc}$ shunt dengan daya $5,5 \mathrm{~kW}, 3000 \mathrm{rpm}$.

ELC yang digunakan adalah ELC dengan spesifikasi sama dengan ELC yang digunakan di PLTMH (duplikat). Dengan demikian hasil uji ini mendekati bila hal tersebut dilakukan pada plant yang sebenarnya.

Karena menggunakan generator dengan kapasitas daya yang lebih rendah maka line reactor yang digunakan harus disesuaikan dengan karak-teristik generator sinkron yang digunakan. Pengesetan ELC dilakukan pada posisi nominal sama seperti yang dilakukan pada PLTMH untuk beban nominal. Ballast (dummy load) digunakan resistor bank sehingga sama pula dengan yang ada di plant, sedangkan beban dalam pengujian ini digunakan beban resistif, dengan demikian pengaruh line reactor terhadap sistem PLTMH yang menggunakan ELC bisa diidentifikasi dengan akurat.

Perhitungan induktansi line reactor untuk generator yang digunakan dalam pengujian dilakukan dengan cara yang sama dengan yang telah disampaikan di atas, sebagai berikut.

1. Memilih harga dasar (base values). Sesuai dengan spesifikasi generator: $\mathrm{VA}_{\text {base }}=5000 \mathrm{VA}, \mathrm{V}_{\text {base }}=380 \mathrm{~V}$, dan $\mathrm{f}_{\text {base }}=50 \mathrm{~Hz}$. Berdasarkan harga-harga dasar ini dapat diturunkan harga-harga dasar arus, impedansi dan induktansi.

2. Menghitung arus fasa stator dasar, IS(base):

$I_{\text {(base) }}=V_{\text {base }} /\left(\sqrt{3} \times V_{\text {base }}\right)=5000 /(\sqrt{3} x$ $380)=7.6 \mathrm{~A}$

3. Menghitung Impedansi stator dasar, $\mathrm{Z}_{\mathrm{S} \text { (base) }}$

$\mathrm{Z}_{\mathrm{S} \text { (base) }}=\mathrm{V}_{\text {base }}^{2} / \mathrm{VA}_{\text {base }}=380^{2} / 5000=$ $28,9 \Omega$

Resistansi belitan stator generator adalah $5 \Omega$, sehingga reaktansi bocor belitan stator dapat dihitung sebagai:

$$
\begin{aligned}
& X_{I_{l}}=\sqrt{Z s^{2}-R s^{2}} \\
& X_{L}=\sqrt{28,9^{2}-5^{2}}=28.5 \Omega
\end{aligned}
$$

4. Menghitung Induktansi stator dasar, $\mathrm{L}_{\mathrm{S}}$ (base):

$\mathrm{L}_{\mathrm{S} \text { (base) }}=\mathrm{X}_{\mathrm{LS} \text { (base) }} / \omega_{\text {base }}=28,5 / 314=$ $90,65 \mathrm{mH}$

5. Induktansi line reactor adalah $5 \%$ dari $\mathrm{LS}($ base $)=4,53 \mathrm{mH}$.

Jadi, berdasarkan hitungan ini untuk generator tipikal ini diperlukan line reactor yang mempunyai induktansi $\mathrm{L}=4,53 \mathrm{mH}$. Dengan menggunakan data ini kemudian dilakukan rancang bangun induktor.

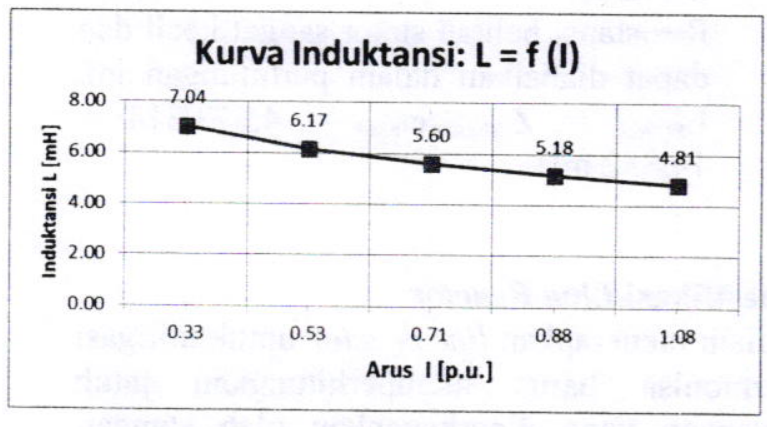

Gambar 15 Kurva induktansi line reactor sebagai fungsi arus 
Hasil pengujian diperoleh informasi seperti yang ditunjukkan kurva induktansi pada Gambar 15.

Dari kurva induktansi terlihat jelas bahwa induktansi line reactor menurun dengan semakin tingginya arus listrik yang melaluinya, Hal ini sangat beralasan mengingat kerapatan magnet (B) tidak berbanding lurus terhadap kuat medan $(\mathrm{H})$ sebagaimana yang ditunjukkan oleh kurva $\mathrm{B}-\mathrm{H}$ suatu bahan. Induktansi $\mathrm{L}=7,04 \mathrm{mH}$ pada arus 0,33 p.u. dan menurun menjadi $4,8 \mathrm{mH}$ pada arus 1,0 p.u. Walaupun tidak sama persis dengan hasil perhitungan $\mathrm{L}$ yang dibutuhkan, yaitu 4,53 $\mathrm{mH}$, namun hal ini bisa dianggap sudah cukup akurat dalam rancang bangun line reactor.

\section{- Pemasangan Line Reactor (LR)}

Ada beberapa cara pemasangan line reactor pada sistem, yaitu langsung pada terminal generator atau pada ballastnya. Cara pertama digunakan bila sumber harmonisa tidak hanya berasal dari ELC dan ballast saja tapi juga dari beban-beban non linier yang berasal dari konsumen. Sedangkan cara kedua diterapkan bila dapat dipastikan bahwa beban konsumen tidak memiliki beban non-linier secara signifikan.

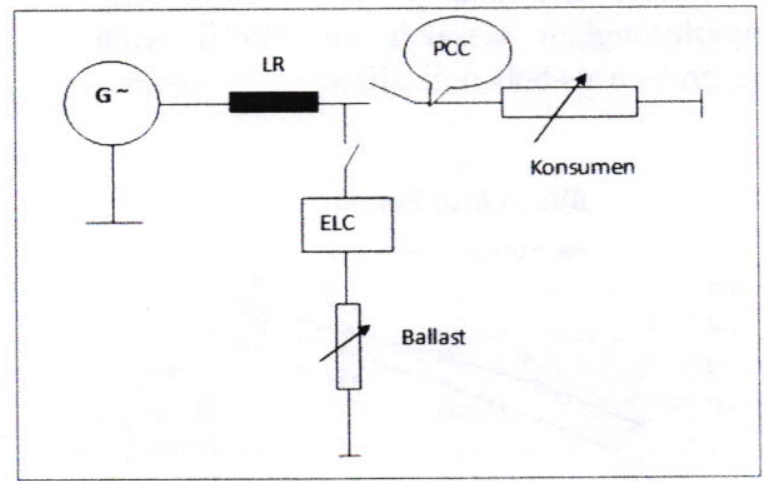

Gambar 16 Diagram skematik peletakan LR

Dalam pengujian ini, karena dianggap suber harmonisa bisa berasal dari konsumen juga, maka diguakan cara yang pertama, yaitu laine reactor disisipkan langsung pada terminal generator seperti ditunjukkan pada Gambar 16.

\subsection{Pengaruh LR terhadap Kualitas Daya pada PCC}

- Pengaruh Pemasangan LR terhadap Harmonisa
Untuk mengetahui pengaruh LR terhadap harmonisa dilakukan di titik PCC dengan dua kali pengukuran. Pengukuran pertama dilakukan ketika generator tanpa LR dan yang kedua dilakukan dengan memasang LR sebagaimana ditunjukkan pada Gambar 16. Similar dengan pengukuran-pengukuran yang dilakukan terdahulu, harmonisa yang terjadi pada titik PCC dilihat berdasarkan variasi pada beban (arus) konsumen. Hasilnya seperti yang ditunjukkan pada Gambar 17 dan 18.

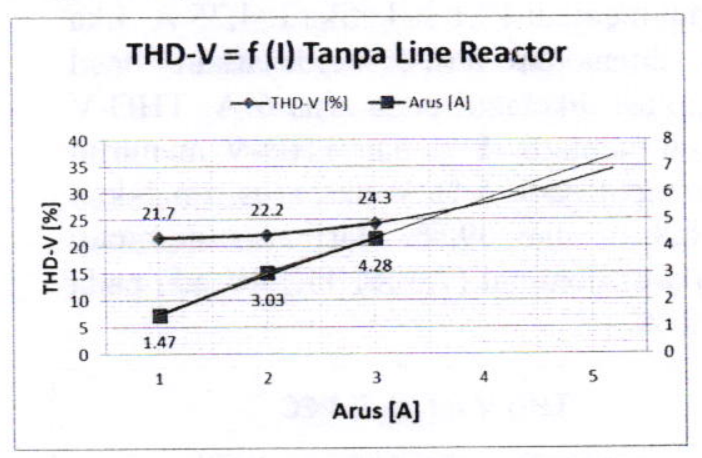

Gambar 17 Kurva THD-V sebagai fungsi arus I, tanpa LR

Gambar 17 menunjukkan kurva harmonisa tegangan THD-V di PCC sebagai fungsi dari arus beban. Dari kurva-kurva ini terlihat bahwa semakin tinggi beban atau arus yang mengalir ke konsumen semakin tinggi pula THD-V secara polynomial. Pada beban ke-1 dengan arus 1,47 A THD-V 21,7\% dan meningkat menjadi $24,3 \%$ pada arus $4,28 \mathrm{~A}$. Jika beban dinaikkan hingga mencapai nominalnya, yaitu ketika $\mathrm{I}=7,6 \mathrm{~A}$, dengan melakukan ekstrapolasi, maka THD-V meningkat menjadi $34 \%$.

Ekstrapolasi dilakukan karena prime mover yang digunakan dalam pengujian ini tidak cukup kuat untuk daya keluaran generator $\mathrm{P}=$ $5000 \mathrm{VA} \times 0,8=4000 \mathrm{~W}$.

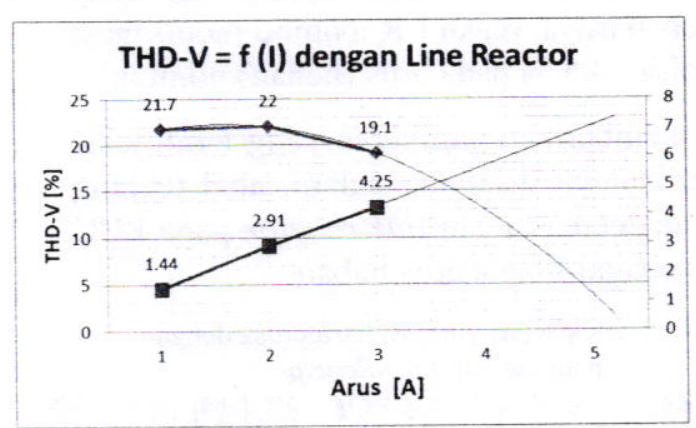

Gambar 18 Kurva THD-V di PCC sebagai fungsi arus beban, dengan LR 
Dari data ini terlihat jelas bahwa THD-V jauh melampaui harga maksimum yang diperkenankan, yaitu 5\%.

Bagaimana keadaannya ketika generator disisipi dengan LR, jawabannya seperti yang ditunjukkan pada Gambar 18.

Ketika arus beban dinaikkan dari 1,44 A menjadi 2,91 A, THD-V mengalami kenaikkan sedikit, yaitu dari $21,7 \%$ menjadi $22 \%$. Dari titik tersebut ketika arus dinaikkan THD-V menurun menjadi $19,1 \%$ ketika I=4,25 A. Jika beban dinaikkan terus, berdasarkan hasil ekstrapolasi diketahui pada arus $6 \mathrm{~A}$, THD-V menurun menjadi $12 \%$ dan THD-V menurun terus sampai pada $5 \%$ ketika arus dinaikkan terus $6,8 \mathrm{~A}$ atau $89,5 \%$ dari arus nominal. Ketika arus nominal (7,6 A) THD-V ada pada posisi $2 \%$.

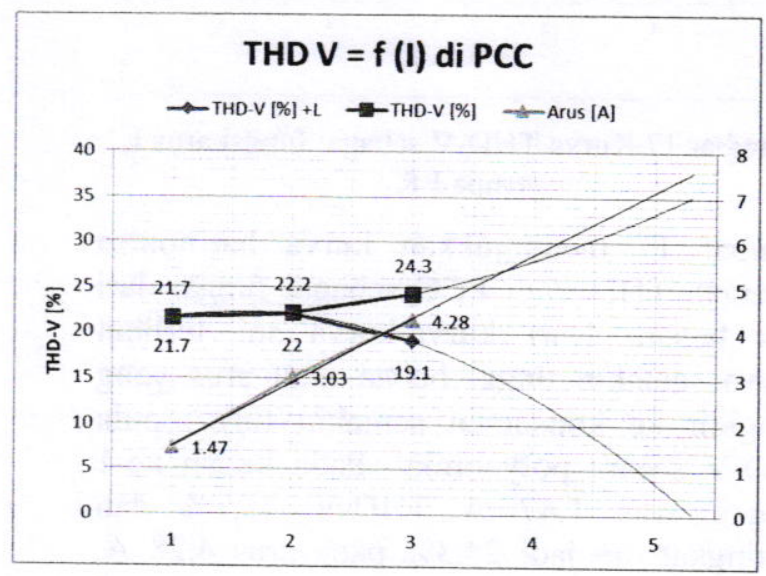

Gambar 19 Pembandingan THD-V tanpa dan dengan LR berdasarkan arus beban

Gambar 19 menunjukkan demikian tinggi peranan dari LR yang dipasang pada sistem. LR secara efektif mampu menurunkan THD-V sejak arus beban pada posisi $3 \mathrm{~A}$ atau sekitar $40 \%$ dari arus nominal. Dan bila ekstrapolasi yang dilakukan sesuai atau mendekati kondisi yang sebenarnya, maka LR mampu memitigasi harmonisa $34.5 \%$ pada arus (beban) nominal.

Untuk memberikan gambaran yang lebih jelas lagi, berikut ini disajikan dalam tabel tentang efektivitas pemasangan line reactor pada PCC sistem sebagai fungsi arus beban.

Tabel 1. Efektivitas mitigasi harmonisa dengan pemasangan Line Reactor

\begin{tabular}{|c|c|c|c|c|c|c|c|c|}
\hline Arus Beban (p.v) & 0.19 & 0.40 & 0.56 & 0.66 & 0.79 & 0.91 & 0.92 & 1.00 \\
\hline THDV Tanpa LR (\%) & 21.7 & 222 & 243 & 26 & 29 & 32.5 & 33.0 & 35.0 \\
\hline THDV dengan LR $(\%)$ & 21.7 & 22 & 19.1 & 16.5 & 11 & 5 & 4 & 0 \\
\hline Migeas $(\%)$ & 0 & 0.2 & 52 & 9.5 & 18 & 27.5 & 29 & 34. \\
\hline
\end{tabular}

Dari tabel 1 kelihatan jelas bahwa LR mulai memberikan kemampuan dalam memitigasi harmonisa sejak arus beban mencapai 0,4 p.u. Kemampuan mitigasinya semakin tinggi dengan semakin tingginya arus beban (semakin rendahnya arus yang mengalir ke ballast). Pada beban sekitar 0.8 pu THD-V menurun menjadi $10 \%$, pada 0,91 pu THD-V menjadi $5 \%$. Jadi, atas dasar data di atas sistem bekerja dengan harmonisa $5 \%$ ke bawah bila sistem dibebani lebih $91 \%$ atau lebih. Ini juga memberikan gambaran bahwa teknik mitigasi ini cukup cocok untuk diterapkan pada sistem yang menggunakan ELC yang dalam operasinya menggunakan rangkaian regulator ac dengan triac atau SCR. Line reactor ini mampu mereduksi harmonisa sampai hampir $35 \%$ pada beban nominal.

\section{- Jatuh Tegangan pada LR}

Satu konsekwensi dari pemakaian Line Reactor dalam sistem ini adalah adanya jatuh tegangan yang cukup besar, tidak ada masalah dengan leading power factor sebagaimana yang terdapat pada Tuned Filter atau Broadband Filter. Tegangan jatuhnya pun tidak setinggi pada Broadband Filter. Walaupun begitu Line Reactor ini mempunyai jatuh tegangan yang relatif besar. Karena itulah dalam pemilihannya harus betul-betul memperhitungkan masalah ini. Profil jatuh tegangan vs arus beban disajikan pada Gambar 20.

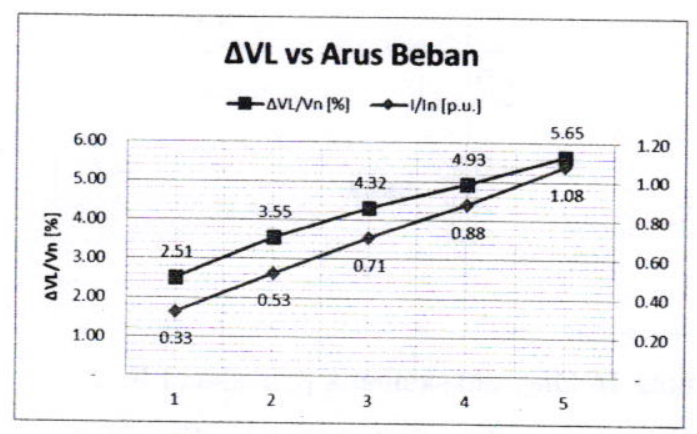

Gambar 20 Jatuh Tegangan (\%) pada LR vs Arus Beban (p.u.)

Terlihat dari Gambar 20 bahwa kenaikan tegangan jatuh $\triangle \mathrm{VL}$ hampir berbanding lurus dengan kenaikan arus beban. Jatuh tegangan $\triangle \mathrm{VL}$ pada arus nominal (1 p.u.) sebesar 4,93 $\%$ dari tegangan nominal $(220 \mathrm{~V})$. Ini sesuai dengan perancangan, di mana LR dibuat berinduktansi $\mathrm{L}=5 \quad \%$ dari induktansi generator. Nilai $5 \%$ ini dimaksudkan agar jatuh tegangan pada beban nominal tidak 
melampaui batas maksimum yang diperkenankan. Atas dasar ini dapat dikatakan bahwa jatuh tegangan LR sesuai dengan rancangan yang dilakukan.

\section{KESIMPULAN.}

Berdasarkan hasil analisis di atas dapat disimpulkan bahwa:

- ELC dengan ballastnya merupakan sumber harmonisa pada sistem PLTMH yang menyebabkan timbulnya permasalahan harmonisa pada PCC (titik sambungan ke beban).

- Teknik mitigasi dengan menggunakan line reactor cukup efektif mengatasi harmonisa hampir $35 \%$ pada arus beban nominal dengan demikian teknik mitigasi ini bisa diterapkan pada PLTMH yang menggunakan ELC (regulator tegangan ac).

- Dibalik keuntungan yang diperoleh, teknik mitigasi yang menggunakan Line Reactor menyebabkan tegangan jatuh yang besarnya sama dengan persentase induktansi dari induktansi base $\left(\mathrm{L}_{\text {base }}\right)$ nya.

\section{DAFTAR ACUAN}

[1] Mashar, Ali, Sodiq, Dja'far, Analisis Harmonisa dari Electronic Load Control (ELC) pada PLTMH, SNP2M, PNJ, 2011.

[2] Hearn, I.R. etal, 1992, A rugged Simplistic Reliable Micro Hydro Generation System, IEEE Proc. of $3^{\text {rd }}$ AFRICON Conference, 22-24 Sep 1992.

[3] Hasan, A., 2007, Pengontrol Beban Elektronik pada Pembangkit Listrik Tenaga Mikrohidro, Jurnal Teltron, Universitas Budiluhur, Vol. 4, No. 2 Juli 2007.

[4] Swamy, Mahesh M, 2007, Understanding Input Harmonics and Techniques to Mitigate Them, Yaskawa Electric America, USA.

[5] Hurdle, Kelvin J, 2009, Harmonic Mitigation Techniques for Low and Medium Voltage Drives, ISA Chapter Meeting January $20^{\text {th }} 2009$

[6] Lundquist, Johan, 2001, Thesis: On System Harmonics in Power System, Chalmers University of Technology, Swede 